\title{
Social Support and Health-Related Quality of Life among Mental Health Service Users in Japan
}

\author{
Yuki Miyamoto ${ }^{1 *}$, Rieko Koichi ${ }^{2}$, Miki Akiyama ${ }^{3}$ and Soichi Takamura ${ }^{4}$ \\ ${ }^{1}$ Department of Psychiatric Nursing, Graduate School of Medicine, The University of Tokyo, 7-3-1 Hongo, Bunkyo, Tokyo 113-0033, Japan \\ ${ }^{2}$ School of Nursing and Nutrition, Shukutoku University, 673 Nitona, Chuo-ku, Chiba 260-8703, Japan \\ ${ }^{3}$ Division of Nursing, Faculty of Healthcare, Tokyo Healthcare University, 4 Chome-1-17 Higashigotanda, Shinagawa, Tokyo 141-0022, Japan \\ ${ }^{4}$ School of Nursing, Seirei Christopher University, 3453 Mikataharacho, Kita Ward, Hamamatsu, Shizuoka 433-8558, Japan
}

Received: October 14, 2014; Accepted: November 14, 2014; Published: November 27, 2014

*Corresponding author: Yuki MIYAMOTO, Department of Psychiatric Nursing, Graduate School of Medicine, The University of Tokyo, 7-3-1 Hongo, Bunkyo, Tokyo 113-0033, Japan, Tel: 81-3-5841-3611; Fax: 81-3-5841-3611; E-mail: yyuki-tky@umin.ac.jp

\begin{abstract}
Aim: This study aimed to describe supporters (social support providers) of mental health service users living in the community, and to determine how the number of supporters affects healthrelated quality of life (HRQOL).

Methods: A cross-sectional survey was conducted using a selfreported questionnaire administered to persons with mental health challenges living in the community. The study was performed in psychiatric social rehabilitation facilities in Japan. Overall, 246 individuals were asked to participate, and 197 responses $(80.1 \%$ of recruited people, $87.6 \%$ of people who gave consent) were analyzed in this study. Short Form-8 (SF-8) was used to assess physical and mental HRQOL. Participants were asked to mark "all the people who support your current community life" from a list consisting of 20 attributions, and to provide the number of people "who support you when you are in real trouble." Multiple linear regression models were used to examine the physical HRQOL (physical component summary score) and mental HRQOL (mental component summary score) in relation to numbers of supporters, controlling for gender, age, diagnosis, psychosocial functioning (Global Assessment of Functioning: GAF score), service satisfaction (Client Satisfaction Questionnaire: CSQ-8 score), and living situation.
\end{abstract}

Results: The mean number of total marked attritions as current community life supporters was $4.9(\mathrm{SD}=2.7)$ and mean number of people who support the participant when in real trouble was 3.0 $(\mathrm{SD}=0.9)$. Number of current supporters was not associated with physical HRQOL, and number of current supporters was negatively associated with mental HRQOL in multiple linear regression analysis. Age was significantly negatively associated with physical HRQOL, and significantly positively associated with mental HRQOL.

Conclusions: Both quantity and quality of social support information is needed to further investigate the association between HRQOL and social support.

Keywords: Community Health Services; Community Psychology; Health Related QOL (HRQOL); Mental Disorders; Mental HRQOL; Physical HRQOL; Psychiatric Social Work; Quality of Life; Social Network; Social Support

\section{Introduction}

In recent times, the importance of community mental health care has received increased recognition. In Japan, a vision for the reform of the mental health care system, which includes downsizing the number of psychiatric beds as one of the primary objectives, was created in 2004 by Japan's Ministry of Health, Labour and Welfare. However, the number of psychiatric beds has not decreased over the last decade [1], and deinstitutionalization of mental health care in Japan is still at an early stage.

Although the progress is slow in Japan, to rebalance the provision of mental health care from institutions to the community is a challenge [2], and the number of community support facilities for persons with disabilities are increasing [3]. Searching for ways to promote deinstitutionalization, and ways to improve well-being and quality of life of persons with mental health challenges are both pressing issues in Japan.

One of the agenda items for this issue is having a place to live in a community. The housing situation is related to quality of life in persons with schizophrenia [4], and housing services have shown greater integration, improvements in quality of life, and reduction in mental illness symptoms [5]. Another important agenda item for better addressing community life issues is how to live in a society. Social support has been indicated to have a role in health maintenance in numerous studies (e.g. [6-8]). In both the general population, and for people with various mental health challenges, social support has been considered to be related to quality of life [9-19], and recovery [20,21].

As individuals with mental health challenges tend to have higher morbidity with physical illness such as metabolic syndrome and respiratory illnesses [22,23], physical health is also an important element in community life. Health-related quality of life (HRQOL) is a health-focused QOL concept that includes subjective health condition, and encompasses aspects of health that influence QOL ratings, allowing comparison between different conditions and illnesses [24-27]. For people with mental 
health challenges, HRQOL has also been shown to benefit from social support [28-30].

Despite the importance of social support in this area, investigations are lacking regarding actual conditions of social support and social networks of persons with mental health challenges living in the community in Japan. For this reason, we asked community-dwelling persons with mental health challenges to answer questions about who supports their life in the community, and how many people would help them when they are in trouble.

Furthermore, we explored the association between social support with sociodemographic characteristics, and both physical and mental HRQOL of community-dwelling persons with mental health challenges.

The aim of present study was to describe the number and types of supporters of people with mental health challenges living in a community. Our second goal was to examine the relationship between number of supporters and physical and mental HRQOL of people with mental health challenges. We expected that the number of supporters would predict the HRQOL of a person with mental health challenges living in a community.

\section{Methods}

\section{Design and data collection}

This cross-sectional study administered self-reported questionnaires to people with mental health challenges living in a community. The study was performed in psychiatric social rehabilitation facilities in Japan with people diagnosed with mental health challenges. Social rehabilitation facilities in Japan include community centers, vocational training centers, group homes, and facilities where staff promote recovery in communitybased settings. In these facilities, rehabilitation training programs, such as social skills training, and job training are provided for the users. For the purpose of this study, researchers and experts in psychiatric community care nominated social rehabilitation facilities for their good practice and called 40 facilities in eight prefectures to seek their cooperation in this study. The survey was conducted from November to December 2004. There were 1,530 psychiatric social rehabilitation facilities and 20,977 users of those facilities in Japan as of October 1, 2004 [31]. The user ratio of males to females was approximately 2:1 in 2004 [32], and it was reported that individuals with schizophrenia accounted for $73 \%$ to $82 \%$ of the users of psychiatric social rehabilitation facilities [33].

Participants were recruited from social rehabilitation facilities for people with mental health challenges in Japan. Overall, 246 individuals with mental health challenges were asked to participate in this study, and 225 persons from 39 facilities in eight prefectures gave their written informed consent. Along with the self-reported questionnaire completed by participants, staff members who knew the participating clients in the facility were asked to provide demographic information about the client if the client consented to the survey.

\section{Measures}

Sociodemographic characteristics, health-related QOL (HRQOL), service usage, social support related information was obtained by self-report questionnaires.

Health-related quality of life: Participants answered the Short Form-8 (SF-8) questionnaire [34]. The SF-8 is an 8-item HRQOL scale. The SF-8 is a short version of SF-36, which is a widely-used questionnaire for HRQOL. The SF-8 assess the following items: general health perception, physical functioning, role physical, bodily pain, vitality, social functioning, mental health, and role emotional using Likert scales with 5 or 6 points. Just like SF-36, two primary summary scores, physical and mental component summary scores that represent physical HRQOL and mental HRQOL can be calculated from these eight items in accordance with the scoring rules. Higher summary scores correspond to a better HRQOL. We adopted the Japanese standardized version of SF-8. The summary scores were standardized to have a mean of 50 in the general Japanese population [34].

Social support: Social support information was gathered by originally developed questions. Participants were asked questions regarding current and preferred supporters of their community life. Regarding current supporters, participants were asked to mark "all the people who support your current community life" from the list provided. The list was composed of 20 attributions: families and partners (5 attributions such as parents, siblings, spouse, etc.); friends and neighbors (4 attributions); formal supporters (10 attributions); and "others," and there was an option for "no one."

Participants were also asked to provide the number of people "who support you when you are in real trouble."

Regarding the preferred supporters, participants were asked to list three people the participant wish to be supported by hereafter, in order of preference.

Other sociodemographic information: The Client Satisfaction Questionnaire, eight-item version (CSQ-8) [35,36] was used to measure participants' satisfaction towards the service they are using. CSQ-8 is an eight-item questionnaire using a 4-point Likert scale. The CSQ-8 was scored by summing the individual item scores to produce a range of 8 to 32, with higher scores indicating greater satisfaction.

The data on participants' sociodemographic characteristics were obtained from staff members who knew the participating client. Demographic characteristics included gender, age, hospitalization, financial support (disability pension, welfare payment), number of hospital admissions, total length of hospital stay, and diagnosis.

The Global Assessment of Functioning (GAF) in DSM IV [37] was used to assess the psychosocial functioning of the participant. The GAF score of participant was rated and provided from facility staff. Higher scores indicate better functioning. 


\section{Ethical considerations}

The Ethical Committee of the authors' affiliation approved the study. The staff of the participating facilities informed all clients orally and in writing about the study purpose and method. Participants signed a consent form, with the understanding that participation in the study was voluntary, that they could withdraw at any time for any reason, that the researchers would link the clients and staff data sheets using ID

Table 1: Demographic characteristics of participants [N = 197].

\begin{tabular}{|c|c|c|c|c|}
\hline & & $\mathbf{n}$ & $\%$ & \\
\hline \multirow[t]{3}{*}{ Gender } & Male & 141 & 71.6 & \\
\hline & Female & 52 & 26.4 & \\
\hline & Not provided & 4 & 2.0 & \\
\hline \multirow[t]{6}{*}{ Age } & $20-29$ & 23 & 11.7 & \\
\hline & $30-39$ & 56 & 28.4 & \\
\hline & $40-49$ & 47 & 23.9 & \\
\hline & $50-59$ & 52 & 26.4 & \\
\hline & $60-$ & 18 & 9.1 & \\
\hline & Not provided & 1 & 0.5 & \\
\hline \multirow[t]{6}{*}{ Diagnosis } & Schizophrenia & 150 & 76.1 & \\
\hline & Mood disorder & 14 & 7.1 & \\
\hline & Anxiety disorder & 5 & 2.5 & \\
\hline & Epilepsy & 5 & 2.5 & \\
\hline & Other & 18 & 9.1 & \\
\hline & Not provided & 5 & 2.5 & \\
\hline \multirow[t]{4}{*}{ Living } & With family & 68 & 34.5 & \\
\hline & Group home/Care home & 83 & 42.1 & \\
\hline & Alone & 39 & 19.8 & \\
\hline & Not provided & 7 & 3.6 & \\
\hline \multicolumn{5}{|c|}{ Receiving Welfare Payment } \\
\hline & Yes & 45 & 22.8 & \\
\hline & No & 141 & 71.6 & \\
\hline & Not provided & 11 & 5.6 & \\
\hline \multicolumn{5}{|c|}{ Receiving disability pension } \\
\hline & Yes & 107 & 54.3 & \\
\hline & No & 81 & 41.1 & \\
\hline \multirow{2}{*}{\multicolumn{2}{|c|}{ Not provided }} & 9 & 4.6 & \\
\hline & & Mean & SD & {$[\min -\max ]$} \\
\hline Numbe & $f_{\text {hospital admissions }}{ }^{a}$ & 3.1 & 3.2 & [0-19] \\
\hline Total lengt & ff hospital stay (months) ${ }^{b}$ & 49.1 & 80.3 & {$[0-504]$} \\
\hline Global Asse & ment of Functioning $(\mathrm{GAF})^{\mathrm{c}}$ & 54.2 & 22.8 & {$[0-91]$} \\
\hline Client Satisf & tion Questionnaire (CSQ)-8 & 23.7 & 3.9 & {$[9-32]$} \\
\hline Physic & component summary & 48.4 & 7.1 & {$[24.8-64.0]$} \\
\hline Ment & component summary & 45.2 & 9.0 & [16.6-60.5] \\
\hline
\end{tabular}

${ }^{a} n=192 \cdot{ }^{b} n=188 \cdot{ }^{c} n=193 \cdot{ }^{d} n=187$. numbers, and that the researchers would not retain identifiable information. Participating clients gave written consent, and staff respondents provided consent by responding and mailing back the questionnaires.

\section{Statistical analysis}

Descriptive statistics were used to present basic information about the participants. The number of people who support a participant's current community life was calculated by summing the numbers of marked attributions. Correlation coefficients between number of supporters in current community life and "number of people who support you when you are in real trouble" were calculated.

The responses in the SF-8 questionnaire were summarized into a physical component summary and a mental component summary scores using the Japanese algorithm in the SF-8 manual [34]. Multiple linear regression models were used to examine the physical HRQOL (physical component summary score) and mental HRQOL (mental component summary score) in relation to number of supporters, controlling for gender, age, diagnosis, psychosocial functioning (GAF score), service satisfaction (CSQ8 score), and living situation (living with family/not, and living alone/not).

A p-value of $<0.05$ was considered statistically significant for all analyses. Statistical analyses were conducted using STATA 12.1.

\section{Results \\ Participant characteristics}

Among 225 persons who gave written informed consent, one person failed to complete his/her questionnaire, and 27 persons did not mark any of the current supporter options (including "no one"). After excluding these 27 responses, the responses of 197 participants ( $80.1 \%$ of recruited people, $87.6 \%$ of people who gave consent) were analyzed in this study.

Participant ages ranged from 21 to 76 years old (mean=43.7 years, $\mathrm{SD}=11.7)$. Other demographic characteristics of participants in this study are shown in Table 1.

\section{People who support participants' community life}

Table 2 lists participants' current community life supporters, and preferred supporters hereafter. Three-fourths of participants marked facility staff in the facility they are using as supporters of their community life. Psychiatrists, peer facility users, and parents were also marked from more than half of the participants as their community life supporters.

Formal supporters or families were selected as $1^{\text {st }}$ choice supporters in community life hereafter. Especially, facility staff and parents were preferred.

The number of supporters of current community life, and number of people who support the participant in real trouble are shown in Table 3. The mean number of total marked attritions as current community life supporters was 4.9 (SD=2.7) and mean number of people who support the participant when in real trouble was $3.0(\mathrm{SD}=0.9)$. 
Table 2: Participants' current community life supporters and preferred supporters hereafter [N = 197].

\begin{tabular}{|c|c|c|c|c|c|c|c|c|c|}
\hline & \multirow{2}{*}{\multicolumn{2}{|c|}{ Community life supporters ${ }^{a}$}} & & \multicolumn{6}{|c|}{ Preferred supporters hereafter ${ }^{b}$} \\
\hline & & & & \multicolumn{2}{|c|}{$1^{\text {st }}$ choice } & \multicolumn{2}{|c|}{$2^{\text {nd }}$ choice } & \multicolumn{2}{|c|}{$3^{\text {rd }}$ choice } \\
\hline & $\mathrm{n}$ & $\%$ & & $\mathrm{n}$ & $\%$ & $\mathrm{n}$ & $\%$ & $\mathrm{n}$ & $\%$ \\
\hline Families and Partners & & & Total & 60 & 30.5 & 38 & 19.3 & 38 & 19.3 \\
\hline Parents & 100 & 50.8 & & 30 & 20.0 & 7 & 4.6 & 13 & 9.2 \\
\hline Siblings & 84 & 42.6 & & 13 & 8.7 & 20 & 13.1 & 10 & 7.0 \\
\hline Spouse & 16 & 8.1 & & 3 & 2.0 & 5 & 3.3 & 3 & 2.1 \\
\hline Partner & 16 & 8.1 & & 5 & 3.3 & 2 & 1.3 & 5 & 3.5 \\
\hline Other Family & 22 & 11.2 & & 9 & 6.0 & 4 & 2.6 & 7 & 4.9 \\
\hline Friends and Neighbors & & & Total & 9 & 4.6 & 31 & 15.7 & 33 & 16.8 \\
\hline Friends & 83 & 42.1 & & 5 & 3.3 & 9 & 5.9 & 13 & 9.2 \\
\hline Peer facility users & 108 & 54.8 & & 2 & 1.3 & 21 & 13.7 & 17 & 12.0 \\
\hline Neighbors & 24 & 12.2 & & 0 & & 1 & 0.7 & 1 & 0.7 \\
\hline Landlord & 20 & 10.2 & & 2 & 1.3 & 0 & & 2 & 1.4 \\
\hline Formal Supporters & & & Total & 67 & 34.0 & 80 & 40.6 & 65 & 33.0 \\
\hline Facility staff & 147 & 74.6 & & 34 & 22.7 & 35 & 22.9 & 25 & 17.6 \\
\hline Psychiatrists & 131 & 66.5 & & 18 & 12.0 & 25 & 16.3 & 25 & 17.6 \\
\hline Hospital case workers & 57 & 28.9 & & 1 & 0.7 & 4 & 2.6 & 6 & 4.2 \\
\hline Psychiatric social worker & 47 & 23.9 & & 4 & 2.7 & 4 & 2.6 & 3 & 2.1 \\
\hline Welfare case workers & 30 & 15.2 & & 6 & 4.0 & 7 & 4.6 & 2 & 1.4 \\
\hline Home visiting nurses & 26 & 13.2 & & 2 & 1.3 & 2 & 1.3 & 3 & 2.1 \\
\hline Public health nurses & 13 & 6.6 & & 0 & & 1 & 0.7 & 1 & 0.7 \\
\hline Local welfare commissioners & 8 & 4.1 & & 1 & 0.7 & 1 & 0.7 & 0 & \\
\hline Home helpers & 5 & 2.5 & & 1 & 0.7 & 1 & 0.7 & 0 & \\
\hline Volunteers & 16 & 8.1 & & 0 & & 0 & & 0 & \\
\hline Other & 13 & 6.6 & & 14 & 9.3 & 4 & 2.6 & 6 & 4.2 \\
\hline No one & 2 & 1.0 & & - & & - & & - & \\
\hline not provided & - & & & 47 & 23.9 & 44 & 22.3 & 55 & 27.9 \\
\hline
\end{tabular}

a Participants were asked to mark "all the people who support your current community life" from the list provided. The list was composed of 21 options: family and partner (5), friends and neighbors (4), formal supporters (10), other, and no one.

${ }^{\mathrm{b}}$ Participants were asked to list three people the participant wish to be supported by hereafter, in order of preference.

Correlation coefficient between number of supporters in current community life (families and friends; formal supporters; and total) and number of people that would be of support in real trouble was $0.24(\mathrm{p}=0.001) ; 0.16(\mathrm{p}=0.029)$; and $0.23(\mathrm{p}=0.002)$, respectively.

\section{Is the number of supporters a predictor of health- related quality of life?}

A multiple linear regression analysis with adjustment for gender, age, psychosocial functioning, service satisfaction, and living situation predicting physical and mental HRQOLs are shown in Table 4. There was no significant relationship between physical HRQOL score and number of current supporters $(B=-0.06, p=0.744)$, and a significant negative relationship was shown between number of current supporters and mental HRQOL score $(B=-0.54, p=0.022)$.
The number of people who will be support in real trouble was not significantly associated with HRQOL.

Age, satisfaction towards using service, and living situations affected physical and mental HRQOL differently. Age was negatively associated with physical HRQOL, and positively associated with mental HRQOL. Living alone was negatively and significantly associated with mental HRQOL. The CSQ-8 score was positively related to mental HRQOL.

In the model entering number of family \& friend supporters, and formal supporters as separate independent variables, both coefficients predicting mental HRQOL were not significant and negative $(B=-0.47, p=0.320 ; B=-0.57, p=0.148$, respectively). The adjusted $\mathrm{R}$-squared value was lower (Adj $\mathrm{R}^{2}=0.224$ ) than the model that entered total number of current supporters. 
Table 3: Number of people who support participants $\quad[\mathrm{N}=197]$.

\begin{tabular}{|c|c|c|c|c|c|c|}
\hline \multicolumn{7}{|c|}{ Number of people who support current community life a } \\
\hline & \multicolumn{2}{|c|}{ Family and Friends ${ }^{b}$} & \multicolumn{2}{|c|}{ Formal Supporters } & \multicolumn{2}{|c|}{ Total $^{\mathrm{c}}$} \\
\hline & $\mathrm{n}$ & $\%$ & $\mathrm{n}$ & $\%$ & $\mathrm{n}$ & $\%$ \\
\hline None & 24 & 12.2 & 20 & 10.2 & 2 & 1.0 \\
\hline 1 & 41 & 20.8 & 35 & 17.8 & 20 & 10.2 \\
\hline 2 & 47 & 23.9 & 55 & 27.9 & 17 & 8.6 \\
\hline 3 & 46 & 23.4 & 37 & 18.8 & 31 & 15.7 \\
\hline 4 & 24 & 12.2 & 24 & 12.2 & 22 & 11.2 \\
\hline 5 & 9 & 4.6 & 20 & 10.2 & 28 & 14.2 \\
\hline 6 & 3 & 1.5 & 0 & & 23 & 11.7 \\
\hline 7 & 3 & 1.5 & 0 & & 22 & 11.2 \\
\hline 8 & 0 & & 2 & 1.0 & 15 & 7.6 \\
\hline 9 & 0 & & 0 & & 5 & 2.5 \\
\hline 10 & & & 2 & 1.0 & 5 & 2.5 \\
\hline 11 & & & & & 3 & 1.5 \\
\hline 12 & & & & & 2 & 1.0 \\
\hline 13 & & & & & 1 & 0.5 \\
\hline 14 & & & & & 1 & 0.5 \\
\hline Mean (SD) & & & & & & $.7)$ \\
\hline
\end{tabular}

Number of people who support you when you are in real trouble ${ }^{d}$

\begin{tabular}{ccc} 
& $\mathrm{n}$ & $\%$ \\
\hline 0 & 0 & \\
1 & 18 & 9.1 \\
2 & 23 & 11.7 \\
3 & 82 & 41.6 \\
4 & 65 & 33.0 \\
Not provided & 9 & 4.6 \\
Mean (SD) & & $3.0(0.9)$
\end{tabular}

a Participants were asked to mark "all the people who support your current community life" from the list provided. The list was composed of 21 options: family and partner (5), friends and neighbors (4), formal supporters (10), other, and no one. The numbers of marked attributions were counted. ${ }^{\mathrm{b}}$ Summed marked number of family and partners, and friends and neighbors are shown in this table.

'Summed marked number of family and partners, friends and neighbors, formal supporters, and other.

${ }^{\text {d }}$ Participants were asked to provide the number of people "who support you when you are in real trouble."

\section{Discussion}

People with mental health challenges living in a community who are clients of social rehabilitation facilities in Japan participated in this study. In this study, we described a detailed list of participants' current community life supporters and preferred supporters hereafter. Facility staff, psychiatrists, peer facility users, and parents were marked from more than half of the participants as people who are supporting their current community lives. Participants preferred family members, especially parents, and formal supporters as supporters of their community life hereafter. The number of current supporters did not predict physical HRQOL significantly, and number of current supporters was negatively and significantly associated with mental HRQOL. "Number of people who would support you in real trouble" was not significantly associated with physical or mental HRQOL.

Three-fourths of participants marked facility staff as current community life supporters. This might be natural because participants in this survey were asked to participate in this study by staff of the facility they were using. We could assume that participants were users who have a good relationship with facility staff. Many participants marked psychiatrists as their current life supporters as well as peers and parents. But when it comes to preferred supporters hereafter, friends and neighbors were not selected to a high proportion. This might be due to differences in relationship type and/or density, which we did not measure in this survey.

The mean number of total marked attritions as current 
Table 4: Multiple Linear Regressions predicting health related quality of life (physical component summary and mental component summary) [N=176].

\begin{tabular}{|c|c|c|c|c|c|c|c|c|c|c|}
\hline \multirow[b]{3}{*}{ Variables } & \multicolumn{5}{|c|}{ Physical HRQOL ${ }^{\mathrm{a}}$} & \multicolumn{5}{|c|}{ Mental HRQOL ${ }^{\text {b }}$} \\
\hline & \multirow[b]{2}{*}{ Coefficients } & \multicolumn{2}{|c|}{$95 \% \mathrm{CI}$} & \multirow[b]{2}{*}{$\mathrm{t}$} & \multirow[b]{2}{*}{$\mathrm{p}$-value } & \multirow[b]{2}{*}{ Coefficients } & \multicolumn{2}{|c|}{$95 \%$ CI } & \multirow[b]{2}{*}{$\mathrm{t}$} & \multirow[b]{2}{*}{ p-value } \\
\hline & & Lower & Upper & & & & Lower & Upper & & \\
\hline Constant & 44.01 & 35.12 & 52.90 & 9.78 & $<0.001$ & 19.54 & 8.94 & 30.14 & 3.64 & $<0.001$ \\
\hline Gender $^{c}$ & 0.44 & -1.88 & 2.76 & 0.37 & 0.709 & -0.96 & -3.73 & 1.81 & -0.69 & 0.494 \\
\hline Age & -0.13 & -0.23 & -0.04 & -2.73 & 0.007 & 0.22 & 0.11 & 0.33 & 3.81 & $<0.001$ \\
\hline Diagnosis $^{d}$ & 1.33 & -1.19 & 3.85 & 1.04 & 0.300 & -0.43 & -3.43 & 2.58 & -0.28 & 0.779 \\
\hline GAf & 0.03 & -0.02 & 0.07 & 1.12 & 0.263 & 0.00 & -0.05 & 0.05 & 0.04 & 0.970 \\
\hline CSQ-8 & 0.12 & -0.17 & 0.41 & 0.83 & 0.409 & 0.84 & 0.49 & 1.18 & 4.8 & $<0.001$ \\
\hline Living with family ${ }^{\mathrm{e}}$ & 1.80 & -0.58 & 4.18 & 1.50 & 0.137 & -2.49 & -5.33 & 0.35 & -1.73 & 0.085 \\
\hline Living alone ${ }^{\mathrm{e}}$ & 0.54 & -2.01 & 3.08 & 0.42 & 0.677 & -4.05 & -7.09 & -1.01 & -2.63 & 0.009 \\
\hline Current supporters ${ }^{f}$ & -0.06 & -0.45 & 0.32 & -0.33 & 0.744 & -0.54 & -1.00 & -0.08 & -2.31 & 0.022 \\
\hline \multirow[t]{6}{*}{ Support in real trouble ${ }^{g}$} & 1.18 & -0.05 & 2.41 & 1.90 & 0.059 & 0.81 & -0.66 & 2.28 & 1.09 & 0.277 \\
\hline & \multicolumn{5}{|c|}{$F(9,166)=3.05, p=0.002$} & & \multicolumn{4}{|c|}{$F(9,166)=6.83, p<0.001$} \\
\hline & \multicolumn{5}{|c|}{ R-squared = 0.142} & & \multicolumn{4}{|c|}{ R-squared $=0.270$} \\
\hline & \multicolumn{5}{|c|}{ Adj R-squared = 0.095} & & \multicolumn{4}{|c|}{ Adj R-squared $=0.231$} \\
\hline & \multicolumn{5}{|c|}{ f-squared = 0.166} & & \multicolumn{4}{|c|}{ f-squared $=0.370$} \\
\hline & \multicolumn{5}{|c|}{ Root MSE = 6.721} & & \multicolumn{4}{|c|}{ Root MSE = 8.016} \\
\hline
\end{tabular}

${ }^{a}$ Physical component summary score in Short Form-8; ${ }^{b}$ Mental component summary score using Short Form-8; ${ }^{\mathrm{c}}(0=$ male, $1=$ female $) ;{ }^{\mathrm{d}}(1=$ schizophrenia, $0=$ others $) ;{ }^{\mathrm{e}}(0=$ no, $1=$ yes $) ;{ }^{\mathrm{f}}$ Number of supporters of current community life; ${ }^{\mathrm{N}}$ Number of people who support the participant in real trouble; 95\% CI = 95\% confidence interval; GAF: Global Assessment of Functioning; CSQ-8: Client Satisfaction Questionnaire 8-item version; Root MSE: root mean squared error

community life supporters was $4.9(\mathrm{SD}=2.7)$. In our questionnaire, we did not divide parents into father and mother, and siblings to brothers and sisters, and did not ask regarding the number of supporters belonging to the sameattrition. For example, even if the respondent had many friends, they could only mark one "friends" attrition. Considering this limitation in our questionnaire, the real number of current community life supporters could be larger for our participants. Although it is not adequate to compare the number of supporters in our study directly with other studies that investigated social network size, our results suggest that our participants having 5 or more supporters had larger social network compared to the average social network size of Latinos with mental illness (3 contacts) [11].

The correlation efficient between number of current community life supporters and number of people "who will support you when you are in real trouble" was not high, ranging from 0.16 to 0.24 . This means that the number of people who are participants marked as supporters and number of people who is a participant feels he/she can really count on is not highly related to each other.

The number of current supporters was not associated with physical HRQOL, and number of current supporters was negatively associated with mental HRQOL in multiple linear regression analysis. This means that the quantity of social support was negatively associated with mental HRQOL. This was not consistent with a result that showed a relationship between low levels of social and emotional support and poor HRQOL in the general adult population [30]. One of the possible explanations for this result in our study is that our participants were users of psychiatric social services, and this group might have consisted of people who have high social support. Only two persons $(1 \%$ of our participants) answered that no one is supporting his/ her community life. Another possible explanation would be that people with low mental HRQOL need more social support and regard people around them as "supporters," while people with high HRQOL would not need that much support and they might not regard people around them as "supporters."

Social support had been organized into three categories: social embeddedness, perceived social support, and enacted support [38]. Social embeddedness is related to connections with others, and what we measured in our present study would be categorized as social embeddedness. In Ribas \& Lam's study, quality of social support, not network size, was positively associated with subjective QOL [11], and in Tan et al.'s study, dissatisfaction with overall HRQOL in schizophrenia patients was associated with dissatisfaction with family support [39]. We have to be cautious that the number of supporters does not represent the actual quantity or quality of support received, and also as pointed out by Helgeson [40], perceived support and received support needs to be distinguished from each other. Additionally, we used a physical component summary and mental component summary from the SF-8 questionnaire to measure HRQOL. The SF-8 questionnaire consists of questions regarding "health" including functioning and role, and health-related quality of life in SF-8 and is a different concept from subjective quality of life. We could have added a different kind of quality of life measure besides health-related quality of life to examine comprehensive quality of life. In a future study, a quality assessment of social 
support should also be added, and consideration is needed regarding what aspect of quality of life we want to pursue.

Although we entered age in the regression model as one of the controlling factors, age predicted physical HRQOL negatively, and mental HRQOL positively was an interesting result. Physical health and physical function might decrease as we get older, but gain in mental health might be achieved with aging. Aging of persons of mental health challenges has received some attention lately, and promoting successful aging is an important topic in Japan [41]. Our study results that showed both a physical HRQOL and mental HRQOL association with age might provide background information for this topic.

Our current study has several limitations. First, as we stated earlier, we did not obtain information on the quality of support that the participants received, and satisfaction of support from those supporters. This information might have affected the association between social support and HRQOL. Second, this study did not consider the severity, symptoms of illness, and classification of schizophrenia. It is reported that the quality of life in people with severe mental illness was related to symptoms of illness [10] Taking this in consideration, mental HRQOL especially might have been affected by symptom severity. However, we entered a GAF score as a control variable in the regression model to predict HRQOL.

\section{Conclusion}

Facility staff, psychiatrists, peer facility users, and parents were marked as community life supporters by more than half of the participants who were community-dwelling mental health service users in Japan. Participants preferred families especially parents, and formal supporters as supporters of their community life hereafter. The number of current supporters did not significantly predict physical health-related quality of life (HRQOL), and number of current supporters was negatively and significantly associated with mental HRQOL. Age was significantly negatively associated with physical HRQOL, and significantly positively associated with mental HRQOL. To further investigate the association between HRQOL and social support, both quantity and quality of social support information is needed.

\section{Acknowledgements and Funding}

The authors would like to thank all the participants and staff of the facilities who participated in the study, and all members of the community mental health care research group in the Mirai Shiko Kenkyu Project.

This study was part of the Mirai Shiko Kenkyu Project (Future-oriented research project) funded by the Ministry of Health, Labour and Welfare, Japan.

\section{Declarations}

\section{Ethical approval}

The Ethical Committee of the Graduate School of Medicine, The University of Tokyo, Japan, approved the aims and procedures of this study (1001). Participants signed a consent form, with the understanding that participation in the study was voluntary, that they could withdraw at any time for any reason.

\section{References}

1. Ministry of Health Labour and Welfare Japan. Survey of medical institutions and hospital report, 2013. In: Statistics and Information Department, editor. Tokyo; 2014

2. Ito H, Frank RG, Nakatani Y, Fukuda Y. Mental health care reforms in Asia: the regional health care strategic plan: the growing impact of mental disorders in Japan. Psychiatr Serv. 2013; 64(7): 617-9. doi: 10.1176/appi.ps.201200518.

3. Ministry of Health Labour and Welfare Japan. Survey of social welfare institutions, 2012. In: Statistics and Information Department, editor. Tokyo; 2014.

4. Hansson L, Middelboe T, Sørgaard KW, Bengtsson-Tops A, Bjarnason 0 , Merinder L, et al. Living situation, subjective quality of life and social network among individuals with schizophrenia living in community settings. Acta Psychiatr Scand. 2002; 106(5): 343-50.

5. Stergiopoulos V, Gozdzik A, O'Campo P, Holtby AR, Jeyaratnam J, Tsemberis S. Housing First: exploring participants' early support needs. BMC Health Serv Res. 2014; 14: 167. doi: 10.1186/1472-696314-167.

6. Cobb S. Presidential Address-1976. Social support as a moderator of life stress. Psychosom Med. 1976 Sep-Oct; 38(5): 300-14.

7. Cohen S, Wills TA. Stress, social support, and the buffering hypothesis. Psychol Bull. 1985 Sep; 98(2): 310-57.

8. Kessler RC, Price RH, Wortman CB. Social Factors in psychopathology: stress, social support, and coping processes. Annu Rev Psychol. 1985;36:531-72.

9. Sharir D, Tanasescu M, Turbow D, Maman Y. Social support and quality of life among psychiatric patients in residential homes. The International Journal of Psychosocial Rehabilitation. 2007; 11(1): 85-.

10. Hansson L. Determinants of quality of life in people with severe mental illness. Acta Psychiatr Scand. 2006; 113: 46-50.

11. Ribas AC, Lam CS. Social Support and Quality of life among Latinos with mental illness. J Nerv Ment Dis. 2010 ; 198(2): 137-43. doi: 10.1097/NMD.0b013e3181cc522d.

12. Yanos PT, Rosenfield S, Horwitz AV. Negative and supportive social interactions and quality of life among persons diagnosed with severe mental illness. Community Ment Health J. 2001; 37(5): 405-19.

13. Fleury MJ, Grenier G, Bamvita JM, Tremblay J, Schmitz N, Caron J. Predictors of quality of life in a longitudinal study of users with severe mental disorders. Health Qual Life Outcomes. 2013; 11(1): 92. doi: 10.1186/1477-7525-11-92.

14. Hamaideh S, Al-Magaireh D, Abu-Farsakh B, Al-Omari H. Quality of life, social support, and severity of psychiatric symptoms in Jordanian patients with schizophrenia. J Psychiatr Ment Health Nurs. 2014; 21(5): 455-65. doi: 10.1111/jpm.12112.

15. Goldberg RW, Rollins AL, Lehman AF. Social network correlates among people with psychiatric disabilities. Psychiatr Rehabil J. 2003; 26(4): 393-402.

16. Kunikata H, Mino Y. [Quality of life and schizophrenia. A review of the literature] (in Japanese). Nihon Koshu Eisei Zasshi. 2003; 50(5): 377 88.

17. Lanfredi M, Candini V, Buizza C, Ferrari C, Boero ME, Giobbio GM, et al. The effect of service satisfaction and spiritual well-being on the quality of life of patients with schizophrenia. Psychiatry Res. 2014; 216(2): 185-91. doi: 10.1016/j.psychres.2014.01.045. 
18. Ritsner M, Arbitman M, Lisker A, Ponizovsky A. Ten-year quality of life outcomes among patients with schizophrenia and schizoaffective disorder II. Predictive value of psychosocial factors. Qual Life Res. 2012; 21(6): 1075-84. doi: 10.1007/s11136-011-0015-4.

19. Panayiotou G, Karekla M. Perceived social support helps, but does not buffer the negative impact of anxiety disorders on quality of life and perceived stress. Soc Psychiatry Psychiatr Epidemiol. 2013; 48(2): 283-94. doi: 10.1007/s00127-012-0533-6.

20. Corrigan P, Phelan S. Social support and recovery in people with serious mental illnesses. Community Ment Health J. 2004; 40(6): 51323.

21. Pernice-Duca F. Family network support and mental health recovery J Marital Fam Ther. 2010; 36(1): 13-27. doi: 10.1111/j.17520606.2009.00182.x.

22. Scott D, Happell B. The high prevalence of poor physical health and unhealthy lifestyle behaviours in individuals with severe mental illness. Issues Ment Health Nurs. 2011; 32(9): 589-97. doi: $10.3109 / 01612840.2011 .569846$.

23. Casey DE. Metabolic issues and cardiovascular disease in patients with psychiatric disorders. The Am J Med. 2005; 118( Suppl 2): 15S-22S.

24. McHorney CA. Health status assessment methods for adults: Past accomplishments and future challenges. Annu Rev Public Health. 1999; 20(1): 309-35.

25.Zubritsky C, Abbott KM, Hirschman KB, Bowles KH, Foust JB, Naylor MD. Health-related quality of life: Expanding a cnceptual framework to include older adults who receive long-term services and supports. Gerontologist. 2013; 53(2): 205-10. doi: 10.1093/geront/gns093.

26. Revicki DA, Kleinman L, Cella D. A history of health-related quality of life outcomes in psychiatry. Dialogues Clin Neurosci. 2014; 16(2): 127-35.

27. Ashing-Giwa K. The contextual model of HRQoL: A paradigm for expanding the HRQoL framework. Qual Life Res. 2005; 14(2): 297307.

28. Chan S, Jia S, Chiu H, Chien W-T, R Thompson D, Hu Y, et al. Subjective health-related quality of life of Chinese older persons with depression in Shanghai and Hong Kong: relationship to clinical factors, level of functioning and social support. Int J Geriatr Psychiatry. 2009; 24(4): 355-62. doi: 10.1002/gps.2129.

29. Ho WWN, Chiu MYL, Lo WTL, Yiu MGC. Recovery components as determinants of the health-related quality of life among patients with schizophrenia: Structural equation modelling analysis. Aust N Z J Psychiatry. 2010; 44(1): 71-84. doi: 10.3109/00048670903393654.
30. Strine TW, Chapman DP, Balluz L, Mokdad AH. Health-related quality of life and health behaviors by social and emotional support. Their relevance to psychiatry and medicine. Soc Psychiatry Psychiatr Epidemiol. 2008; 43(2): 151-9.

31. Ministry of Health Labour and Welfare Japan. Survey of Social Welfare Institutions, 2004. In: Statistics and Information Department, editor. Tokyo; 2006.

32. Ministry of Health Labour and Welfare Japan. Health facilities and hospitals survey, 2006 [in Japanese]. In: Department of Health and Welfare for Persons with Disabilities, editor. Tokyo; 2010.

33. Hoshino H. Psychiatric vocational training centers [in Japanese]. In: Center for Facilitating Psychiatric Social Rehabilitation, editor. White paper on mental health and welfare. Tokyo: Chuo Houki; 2006. p. 50-1.

34. Fukuhara S, Suzukamo Y. Manual of the SF-8 Japanese version, (in Japanese). Kyoto: Institute for Health Outcomes and Process Evaluation Research; 2004.

35. Attkisson CC, Zwick R. The client satisfaction questionnaire. Psychometric properties and correlations with service utilization and psychotherapy outcome. Eval Program Plann. 1982; 5(3): 233-7.

36. Tachimori H, Ito H. Reliability and validity of the Japanese version of Client Satisfaction Questionnaire (in Japanese). Seishin Igaku (Clinical Psychiatry). 1999; 41(7): 711-7.

37. American Psychiatric Association. Diagnostic and Statistical Manual of Mental Disorders DSM-IV. Washington DC: American Psychiatric Association; 1994.

38. Barrera M Jr. Distinctions between social support concepts, measures, and models. Am J Community Psychol. 1986 1986/08/01; 14(4): 41345 .

39. Tan H-Y, Choo W-C, Doshi S, Lim LC, Kua E-H. A community study of the health-related quality of life of schizophrenia and general practice outpatients in Singapore. Soc Psychiatry Psychiatr Epidemiol. 2004; 39(2): 106-12.

40. Helgeson VS. Two important distinctions in social support: Kind of support and perceived versus received. Journal of Applied Social Psychology. 1993; 23(10): 825-45. doi: 10.1111/j.1559-1816.1993. tb01008.x

41. Niimura H, Nemoto T, Sakuma K, Mizuno M. Promoting "successful aging" in community psychiatric care (in Japanese). Seishin Shinkeigaku Zasshi. 2011; 113(4): 380-6. 